\title{
Effect Analysis of Vehicle System Parameters on Dynamic Response of Pavement
}

\author{
Rong-xia Xia, ${ }^{1}$ Jin-hui $\mathrm{Li}^{2}{ }^{2}$ Jie $\mathrm{He},{ }^{3}$ and Deng-feng $\mathrm{Shi}^{3}$ \\ ${ }^{1}$ College of Engineering, Nanjing Agricultural University, Nanjing, Jiangsu 210031, China \\ ${ }^{2}$ College of Vehicle and Motive Power Engineering, Henan University of Science and Technology, Luoyang 471003, China \\ ${ }^{3}$ School of Transportation, Southeast University, Nanjing, Jiangsu 210096, China
}

Correspondence should be addressed to Jie He; hejie@seu.edu.cn

Received 9 March 2015; Revised 21 June 2015; Accepted 28 June 2015

Academic Editor: Payman Jalali

Copyright (C) 2015 Rong-xia Xia et al. This is an open access article distributed under the Creative Commons Attribution License, which permits unrestricted use, distribution, and reproduction in any medium, provided the original work is properly cited.

\begin{abstract}
In order to study the damage of a semirigid pavement under vehicle loads with varied parameters, the random dynamic loads applied on the pavement by a running vehicle were computed with two degrees of freedom, quarter-vehicle model, and then a three-dimensional finite element analysis model of semirigid asphalt pavement was established. With the peak stress index of each pavement layer, the effect of varied vehicle parameters on pavement response was studied. The results indicated that the stress wave frequency of each pavement layer was similar to that of the dynamic random load, and, with increased pavement depth, the wave effect decreased. The pavement response increased with increased suspension stiffness and tire stiffness and decreased with increased suspension damping and tire damping. Furthermore, compared to the stiffness, the response variation induced by the damping was orders of magnitude lower. Compared with the traditional time response analysis method, the peak response analysis of the pavement structure was more scientific, rational, and intuitive, which could be useful for the study of vehicle-pavement interaction and road damage.
\end{abstract}

\section{Introduction}

Heavy traffic and overloaded transportation systems have accelerated road damage. In order to reduce the damage caused by vehicles, the study of vehicle dynamic loads and pavement response has become a major interest to automotive designers and highway management departments, particularly with regard to the impact of different vehicle types, suspension systems, speed, road surface roughness, pavement structure parameters, and so forth.

In order to analyze the effect of vehicle system parameters on the pavement dynamic response, it is necessary to combine the vehicle subsystem and pavement subsystem into a single parameter. At present, there are two major research methodologies in this field. One is the coupling method, which considers the vehicle subsystem and road subsystem to be a coupled system based on the hypothesis of locomotion and the track coupling effect. The other methodology is the decoupling method, which constructs the vehicle and pavement models separately, obtains the vehicle dynamic loads induced by road surface roughness, and then investigates the pavement dynamic response under vehicle loads. In the vehicle-pavement coupling method, the road surface roughness is usually simplified as a harmonic wave function because of the complexity of the model [1-3]. In the vehicle-pavement decoupling method, the vehicle load is simplified either as a harmonic load or as a moving constant load [4-6]. Neither of these methodologies fully represents the actual vehicle-pavement system.

Recent research $[7,8]$ shows that because of the differences between the vibration modes of the vehicle and pavement systems, as well as the differences between the velocities of the vehicle and pavement elastic waves, the coupling effect between the vehicle and pavement is very weak. Considering the random features of the road surface roughness and the weak coupling characteristics of the vehicle and pavement systems [9-11], a systematic analysis method for studying vehicle and pavement interaction is described in this paper, 


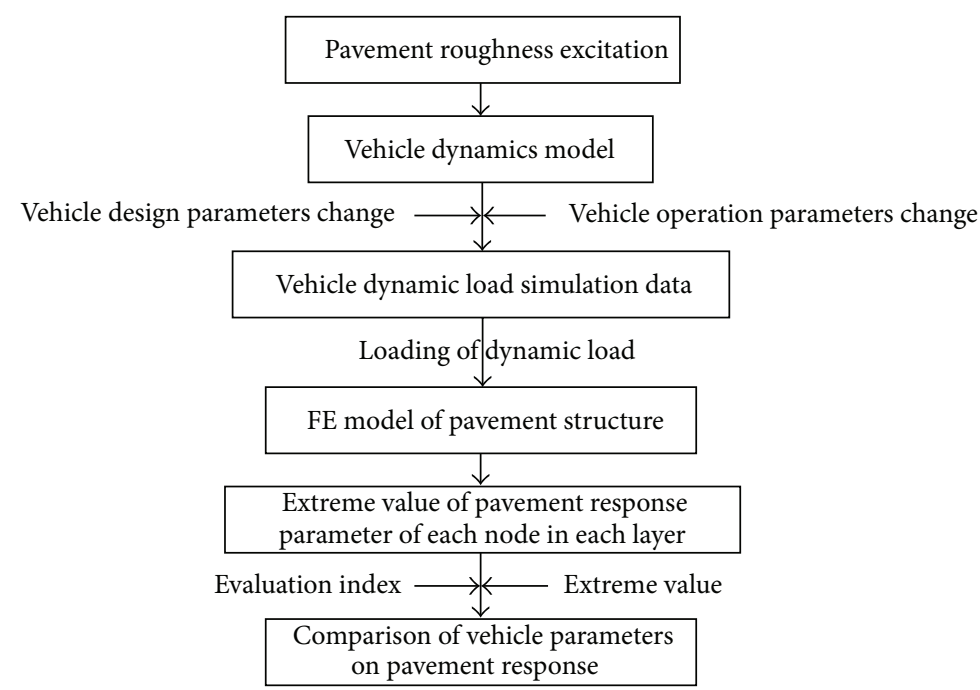

FIgure 1: Analysis method.

as shown in Figure 1. This includes simulations of actual dynamic load characteristics and analyses of the dynamic response of pavement under random loading. The basic steps of this analysis method are as follows. First, the road irregularity excitation model and vehicle vibration model are established, allowing for the determination of the random dynamic vehicle loading. Second, the semirigid asphalt pavement three-dimensional finite element (FE) analysis model is constructed based on the theory of layered elastic systems. Third, considering the mobility and dynamic characteristic of the random vehicle load, the loading is applied to the pavement surface. The distribution law of pavement extreme value nodal response for each layer is analyzed. Finally, taking the peak value on the extreme value distribution curve of response parameters, such as stress, strain, and the comparison index, the impact of vehicle parameters on the pavement is compared and analyzed.

\section{Vehicle Random Dynamic Load Simulation}

Several vehicle dynamics models exist, such as the single wheel model with two degrees of freedom, the half vehicle model with four degrees of freedom, the whole vehicle model with seven degrees of freedom, and the virtual prototype vehicle model. The relevant studies $[10,12,13]$ have shown that the single wheel model is powerful in simulating vehicle dynamic load in the vehicle-pavement interaction field. This model is used without the loss of generality as shown in Figure 2. In this figure, $m_{s}$ is the sprung mass, $m_{t}$ is the unsprung mass, $k_{s}$ is the spring stiffness coefficient, $k_{t}$ is the tire stiffness coefficient, $c_{s}$ is the shock absorber damping coefficient, $c_{t}$ is the tire damping coefficient, $x_{s}$ and $x_{t}$ are the vertical displacements of the sprung and unsprung pavement masses, respectively, and $x_{g}$ is the vertical pavement roughness. In the following analysis, the vehicle parameters are based on the right side rear axle of a Yellow River JN150 heavy truck with full loading. In this case, the vehicle system parameters are as follows: $m_{s}=4450 \mathrm{~kg}, m_{t}=550 \mathrm{~kg}$,

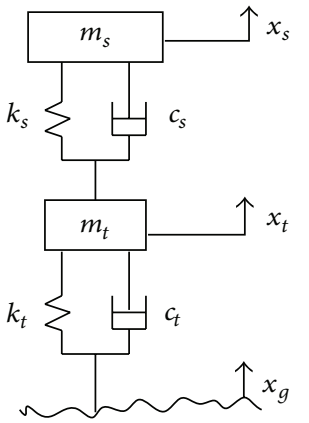

FIgURE 2: Two degrees of freedom vehicle model.

$k_{s}=1000 \mathrm{kN} / \mathrm{m}, c_{s}=15 \mathrm{kNs} / \mathrm{m}, k_{t}=1750 \mathrm{kN} / \mathrm{m}$, and $c_{t}=2 \mathrm{kNs} / \mathrm{m}$.

Based on Newton's second law, the kinematics differential equation is described as follows:

$$
\begin{aligned}
m_{s} \ddot{x}_{s}= & -k_{s}\left(x_{s}-x_{t}\right)-c_{s}\left(\dot{x}_{s}-\dot{x}_{t}\right), \\
m_{t} \ddot{x}_{t}= & k_{s}\left(x_{s}-x_{t}\right)+c_{s}\left(\dot{x}_{s}-\dot{x}_{t}\right)-k_{t}\left(x_{t}-x_{g}\right) \\
& -c_{t}\left(\dot{x}_{t}-\dot{x}_{g}\right) .
\end{aligned}
$$

Based on automobile theory, the vehicle random dynamic load $F_{t}$ is expressed as

$$
F_{t}=F_{d}+G
$$

where $F_{d}$ is the additional dynamic load of the tire, $F_{d}=$ $k_{t}\left(x_{t}-x_{g}\right)+c_{t}\left(\dot{x}_{t}-\dot{x}_{g}\right)$, and $G$ is the vehicle static load, $G=\left(m_{s}+m_{t}\right) g$.

There are several methods for modeling pavement roughness, such as the harmonic superposition method, taking the integral of white noise, filtering white noise, and the AR method [12]. Because the method of filtering white noise is well understood and has a wide application range, we selected 


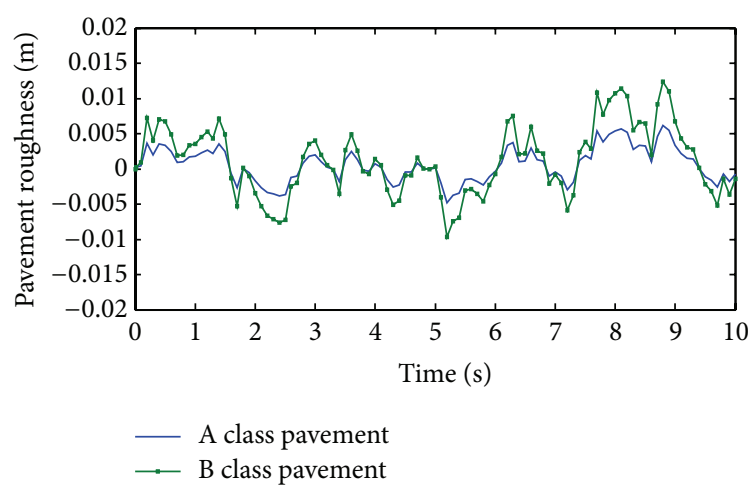

(a) Time domain simulation curve

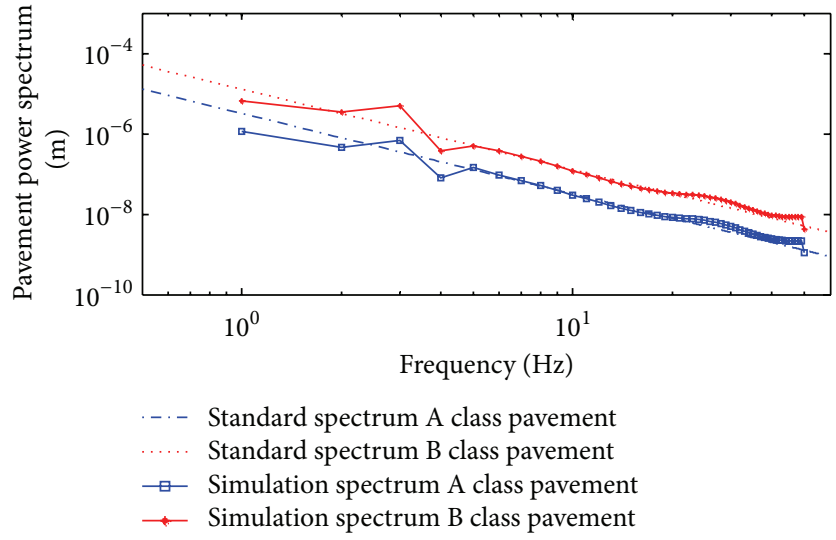

(b) Frequency domain comparison

FIGURE 3: Generation and verification of random road surface.

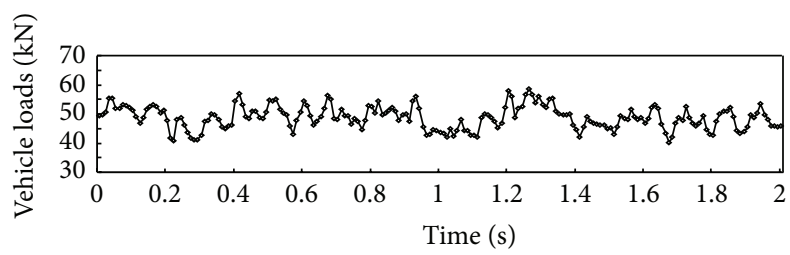

(a) Dynamic load curve

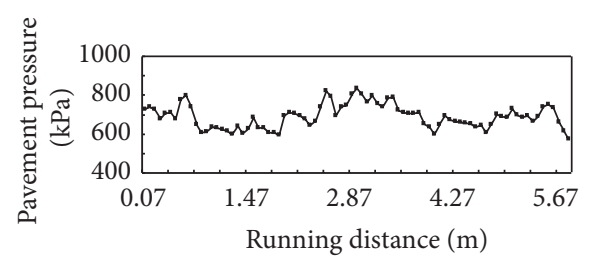

(b) Loading curve

FIGURE 4: Random dynamic load of vehicle with original parameters.

it to simulate irregularity excitation of the road. Its differential equation is as follows:

$$
\dot{x}_{g}(t)=-2 \pi f_{0} x_{g}(t)+2 \pi \sqrt{G_{0} v_{0}} w(t)
$$

where $x_{g}$ is the road roughness displacement, $f_{0}$ is the cutoff frequency, $G_{0}$ is the road roughness coefficient, $v_{0}$ is the vehicle speed, and $w(t)$ is the Gauss white noise with zero mean.

MATLAB/Simulink software was used to model both the road excitation and the vehicle random dynamic load. In view of the convergence, the vehicle speed is $10 \mathrm{~m} / \mathrm{s}$ and the time step is $0.01 \mathrm{~s}$ in performed simulation throughout this study. Figure 3(a) shows the time domain simulation curves for A and B grade road roughness. Figure 3(b) provides a road surface roughness spectral analysis for standard grade road at a random surface elevation and GB7307-87. Based on the spectral density contrast curve as shown in Figure 3(b), it can be seen that generated pavement can be used as a random dynamic input loading analysis.

Figure 4(a) displays the random dynamic load curve used to obtain the original vehicle parameters of the $20 \mathrm{~m}$ space range. The dynamic tire loads $6 \mathrm{~m}$ before and after the load peak (pavement model in this paper is about $6 \mathrm{~m}$ long) selected from Figure 4(a) were used to generate the vehicle random loads for the pavement loading ( $\mathrm{B}$ grade road surface), as shown in Figure 4(b).

\section{Finite Element Model of Pavement Structure}

According to the mechanical characteristics, the pavement structure can be divided into flexible, rigid, and semirigid pavement. The semirigid asphalt pavement comprises the largest proportion of the high-grade highway in China. According to the elastic layered system theory, we have developed a FE model for semirigid pavement. The pavement includes four layers: surface course, base course, subbase course, and soil base course, as shown in Table 1. The material parameters are based on an actual pavement structure as described in the Expressway of Jinan-Qingdao [4].

For convenience of analysis, the pavement FE model is based on four hypotheses. (1) Each course has homogeneous, isotropic linear elastic/viscoelastic materials. (2) The horizontal size and depth of soil base course are infinite, while the thickness of each course above the soil base course is limited, with infinite horizontal size. (3) The traffic load is applied on the road surface; and the resulting stress and strain in the pavement of infinite distance in the vertical direction and in the horizontal direction are zero. (4) The interface between the pavement layers, as well as the interface displacement under vehicle loading, is completely continuous.

For simplicity, the length, width, and height of the pavement FE model are $6.02 \mathrm{~m}, 4.08 \mathrm{~m}$, and $1.58 \mathrm{~m}$, respectively. The Solid185 element (an 8-node solid element) was used as the mesh element for the model. Considering the computational efficiency and accuracy, a fine mesh was applied in the vehicle running area in the center of the road ( $x$-direction 
TABLE 1: Parameters of semirigid asphalt pavement.

\begin{tabular}{lccccc}
\hline Layer & Thickness $/ \mathrm{m}$ & Modulus of elasticity $/ \mathrm{MPa}$ & Poisson's ratio/ $\mu$ & ${\text { Density } / \mathrm{kg} \cdot \mathrm{m}^{-3}}$ Damping rate $/ \%^{-3}$ \\
\hline Surface course & 0.18 & 1200 & 0.25 & 2600 & 0.05 \\
Base course & 0.2 & 2000 & 0.25 & 2300 & 0.05 \\
Subbase course & 0.2 & 800 & 0.25 & 1932 & 0.05 \\
Soil course & 1 & 50 & 0.4 & 1926 & 0.05 \\
\hline
\end{tabular}

of each grid is $0.07 \mathrm{~m}$; $y$-direction is $0.08 \mathrm{~m}$ ), while a coarser mesh was applied to the remaining sections. The pavement layers were merged together to satisfy the assumption of continuity between layers. There were 30450 nodes and 26832 elements in the model. The pavement FE model is shown in Figure 5.

When the vehicle is running in the center of the pavement surface, there is no response at either end of the pavement (far from the vehicle), so a fixed constraint is applied at each end. Because the two transverse sides and the bottom side have a certain viscoelasticity, they are simulated and constrained by three-dimensional spring elements with ANSYS software. The contact imprint between the tire and pavement is the key portion of the FE analysis. In current Chinese pavement design codes, the circular uniform imprint model is recommended. However, the tire contact pressure distribution on the road is not circular and the tire footprint is closer to rectangular [11]. There are two wheels on the truck rear axle and the tire type is 11.00R20. Based on the method proposed in [11], the tire imprint is approximated as a uniform distribution rectangle with the size $0.21 \mathrm{~m} \times 0.32 \mathrm{~m}$. The imprint includes 12 cells in the FE pavement model.

When applying the random dynamic load, the ANSYS/ APDL programming language was used. The loading program consists of the following steps: (1) sampling and editing the random dynamic load data extracted from MAT$\mathrm{LAB} /$ Simulink and saving the data as a text file in order to facilitate the reading and writing operations using ANSYS; (2) defining the load array in ANSYS in accordance with the specified format; (3) reading the defined loading data file in the defined load array using the ${ }^{*}$ TREAD command in ANSYS; (4) determining the loading position for the tire random dynamic load in the wheel region of the FE pavement model and applying the load on the pavement unit using the step loading method to simulate the motion of the vehicle.

\section{Pavement Response Analysis}

In traditional pavement FE analysis, the stress time course changes of a certain node in the pavement model is observed which does not reflect the random characteristics of the vehicle load and the stress distribution of the entire pavement structure [12]. Thus, the extreme value response analysis method realized by ANSYS/APDL programming is presented in this paper to analyze the pavement random response. In order to express the dynamic volatility of pavement structure more clearly, the surface course was divided into three layers further, surface layer, middle layer, and bottom layer, and the thickness of each layer is $0.06 \mathrm{~m}$.

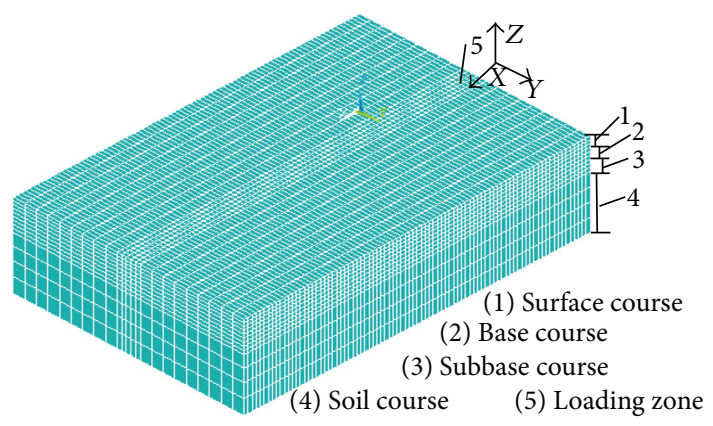

FIGURE 5: Three-dimensional FE model of pavement structure.

Figure 6 shows the extreme value distribution situation for the vertical stress, horizontal stress, transverse stress, and shear stress of each node of each pavement layer under the wheel track centerline. (Note that two extreme values could occur at a given node in the simulation: the maximum value and the minimum value. The larger absolute value was selected and recorded.)

It can be seen from Figure 6(a) that the vertical normal stress decreases with increases in the depth of the pavement structure. This data also indicates that the asphalt surface mainly supports compressive stress and that the maximum vertical compressive stress is in the $0-6 \mathrm{~cm}$ range layer from the asphalt surface. Below the pavement surface, the stress decreases rapidly, reaching a minimum at the top of the soil course (subbase and soil base course interface). Therefore, the asphalt surface layer should have sufficient bearing capacity to reduce the vertical pressure on the soil base course for preventing undesirable deformation.

In Figure 6(b), the maximum horizontal compressive stress occurs on the road surface and then decreases with increasing depth of pavement. The maximum tensile stress occurs at the junction of the base and subbase course, which indicates that this location is most vulnerable to horizontal stress failure under vehicle load. Under dynamic vehicle load, the ultimate tensile stress will cause the pavement to crack from the junction of the base and subbase course and then gradually spread to the upper structure where reflection cracks form in the asphalt surface layer, causing damage to the whole pavement structure.

It can be seen from Figure 6(c) that, similar to the horizontal stress, the maximum transverse compressive stress also lies on the asphalt surface layer with the maximum transverse tensile stress appearing in the junction of the semirigid base and subbase course. Obviously, the transverse stress comprises both compressive and tensile stress, changing 


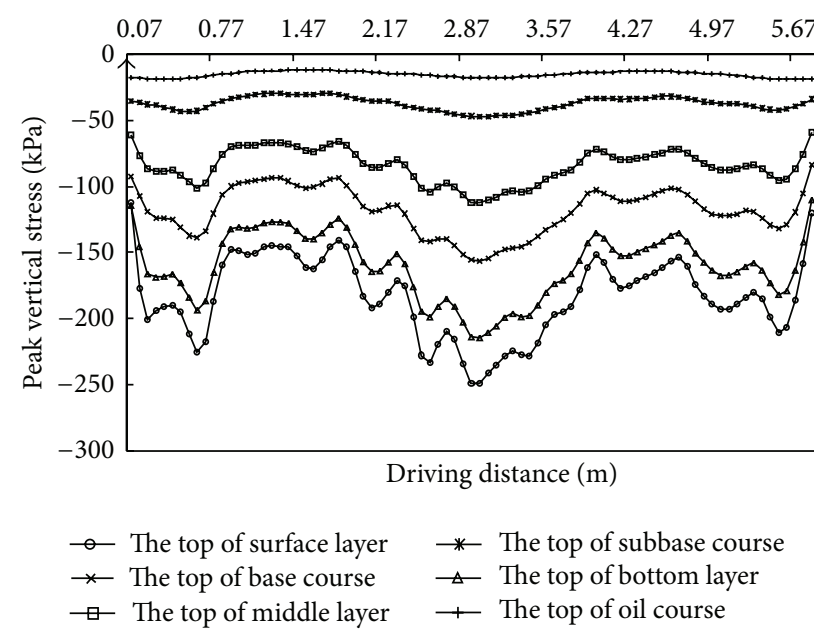

(a) The vertical stress

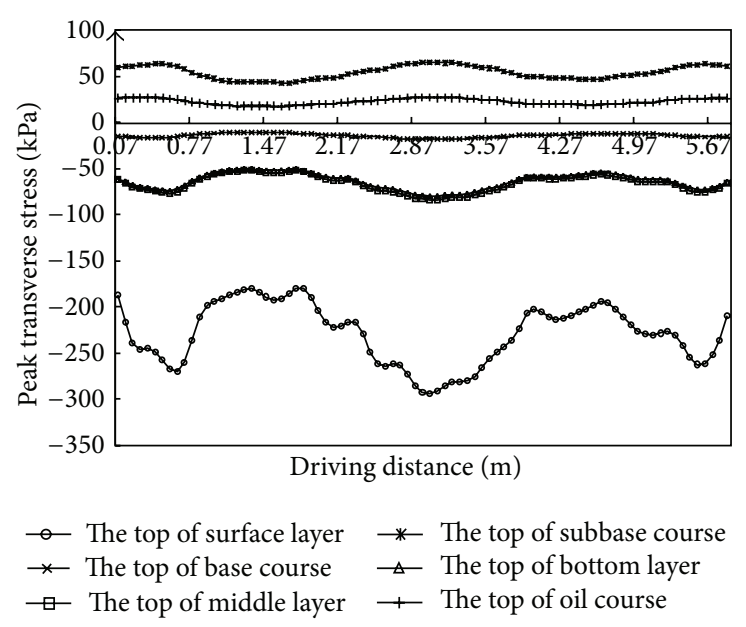

(c) The transverse stress

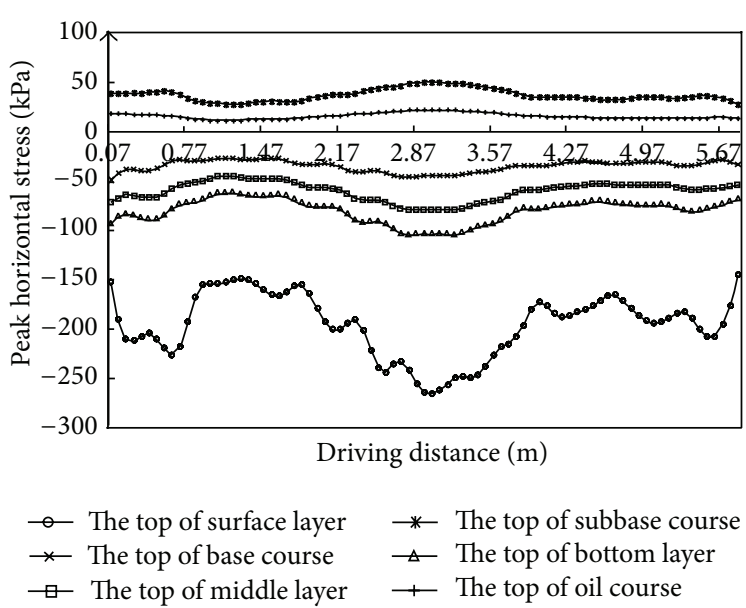

(b) The horizontal stress

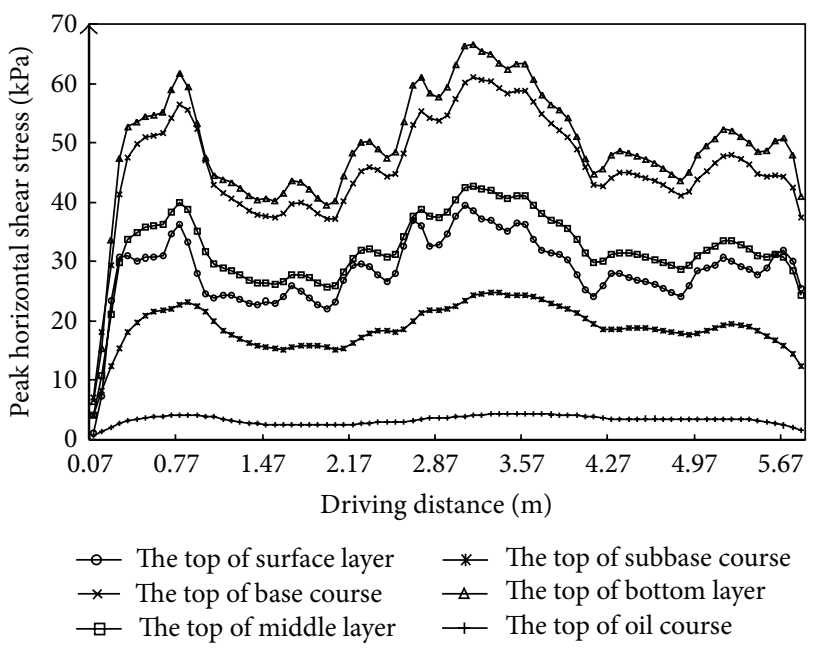

(d) The horizontal shear stress

FIgURE 6: Peak stress distribution of each pavement layer.

alternately, and when compared to the horizontal stress, the transverse dynamic stress is slightly larger. The pavement damage generated by the transverse dynamic stress cannot be ignored.

It can be seen from Figure 6(d) that the horizontal shear stress changes with pavement depth in the asphalt surface layer. That is, the shear stress of the surface layer $(0-6 \mathrm{~cm})$ is relatively small and then increases rapidly near the middle layer $(6-12 \mathrm{~cm})$ where it reaches a maximum at the bottom of the middle layer. The shear stress gradually decreases with increasing pavement depth, reaching the minimum value in soil base. By improving the antishear capacity of the asphalt surface layer, we can effectively reduce pavement failure from wave, slip, shear, and so forth.

All conclusions are consistent with the results of traditional time history analysis of specific pavement nodes $[4,5]$. In addition, Figure 6 indicates that the dynamic response of the pavement structure is fluctuant, with a vibration frequency similar to that of the tire random dynamic load (shown in Figure 4). With increases in pavement depth, the volatility decreases; that is, the farther away it is from the pavement loading region, the weaker the stress fluctuation characteristics are. Thus, the random feature of vehicle loads has a strong influence on the upper pavement structure.

\section{Effects of Vehicle Parameters on Pavement}

Based on vehicle system dynamics theory, the tire dynamic load changes with vehicle system parameters indicated that the pavement dynamic response must be different. To analyze the effect of vehicle parameters on the random dynamic response of pavement, we varied the suspension and tire parameters of the original vehicle to obtain the tire random dynamic simulation loads and then computed the pavement response using the FE method. With this information, the different stress extreme values of each pavement layer could be obtained.

5.1. Effects of Suspension Stiffness. Figure 7 shows the extreme stress distribution at the bottom of the asphalt surface layer 


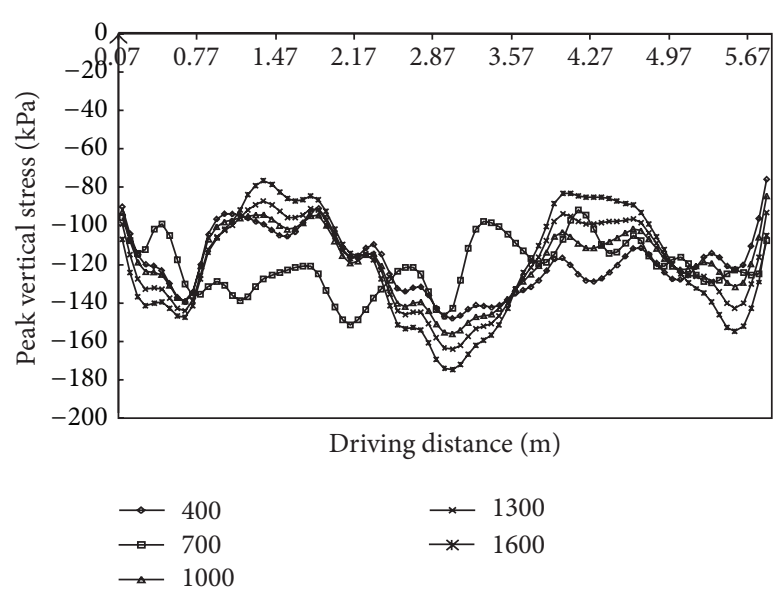

(a) The vertical stress

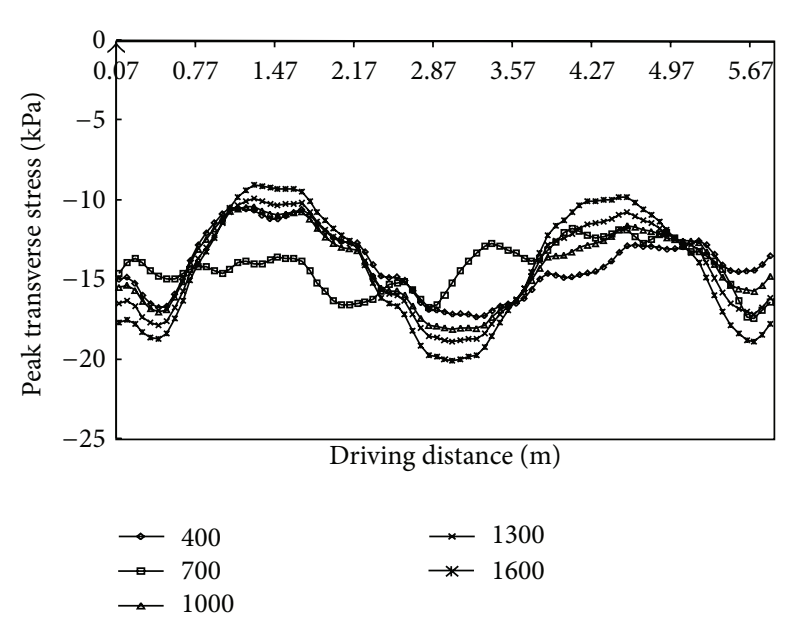

(c) The transverse stress

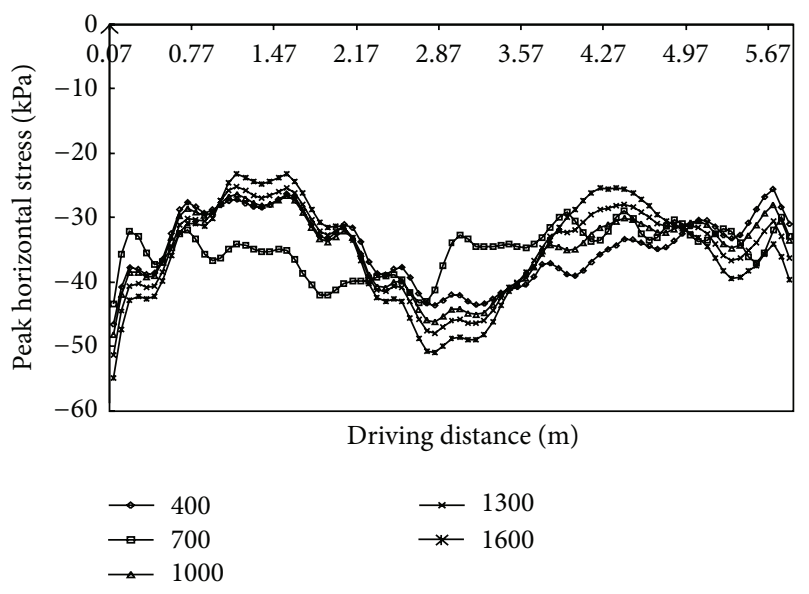

(b) The horizontal stress

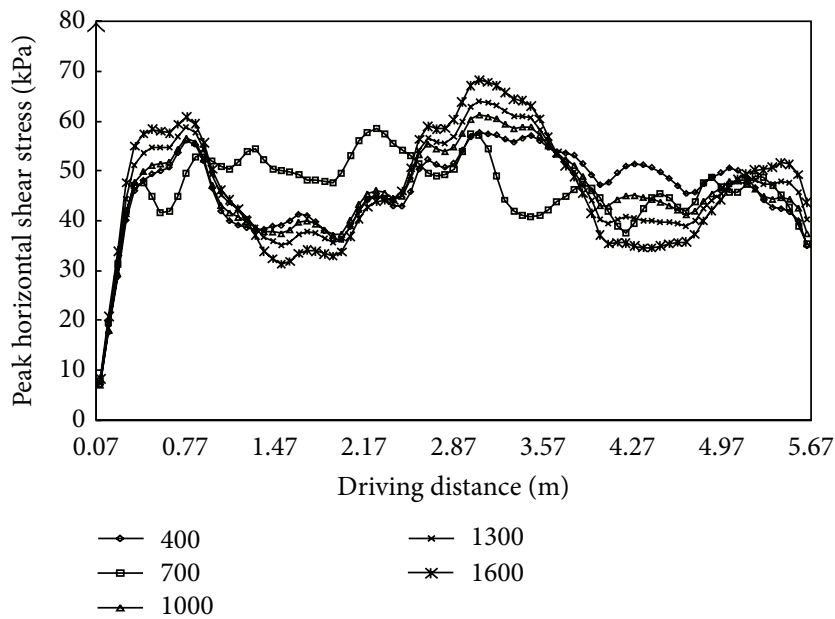

(d) The horizontal shear stress

FIgURE 7: Extreme stress change at the bottom of the surface layer with suspension stiffness.

for different suspension stiffness coefficients. As can be seen from Figure 7, with different suspension stiffness coefficients, the stress extreme curves at the bottom of the surface layer overlap, so these curves lack consistency. The stress curves are similar for tire stiffness coefficients of $400 \mathrm{kN} / \mathrm{m}, 1000 \mathrm{kN} / \mathrm{m}$, $1300 \mathrm{kN} / \mathrm{m}$, and $1600 \mathrm{kN} / \mathrm{m}$; however, the curve for a tire stiffness coefficient of $700 \mathrm{kN} / \mathrm{m}$ has a different shape. The interaction mechanism of the vehicle and pavement is very complicated, and the pavement dynamic response caused by the changing vehicle parameters is highly nonlinear. Neither the simplified methods which consider the vehicle load to be a harmonic load or moving fixed load nor taking the vehiclepavement-foundation system as a simple linear structure is consistent with the actual situation.

Cole and Cebon at the University of Cambridge have pointed out that the degree of damage of the road is determined by the node with the greatest stress and not by the mean destruction of road nodes $[13,14]$. By comparing the peak values in the extreme stress curves for one pavement layer, the influence of different vehicle parameters on pavement response could be obtained. In addition, the vertical deflection and tensile stress of the bottom asphalt layer or semirigid material layer are used as the design criteria in the current specifications of asphalt pavement in China [15]. Furthermore, a standard in the design of city roads should include the calculation of the shear stress of the surface layer materials. So the tensile stress at the bottom of base course and the shear stress at the bottom of surface layer were selected as an index for comparison.

Table 2 shows the effect of suspension stiffness coefficient on the pavement response. It can be seen from Table 2 that the pavement dynamic stress increases with increases in suspension stiffness. When the suspension stiffness increases $60 \%$ from $1000 \mathrm{kN} / \mathrm{m}$ to $1600 \mathrm{kN} / \mathrm{m}$, the peak horizontal tensile stress at the bottom of base course and the shear stress at bottom of surface layer increase $10.91 \%$ and $11.55 \%$, respectively. Compared with the tire stiffness, the effect of suspension stiffness on the pavement dynamic stress response is significant.

5.2. Effect of Suspension Damping. Table 3 shows the effect of the suspension damping coefficient on the pavement 
TABLE 2: Pavement peak stress with suspension stiffness coefficient.

\begin{tabular}{lccccc}
\hline Suspension stiffness coefficient/kN/m & 400 & 700 & 1000 & 1300 & 1600 \\
\hline Tensile stress/Kpa & 47.501 & 48.113 & 51.244 & 52.840 & 56.834 \\
Horizontal shear stress/Kpa & 57.7 & 58.5 & 61.111 & 63.8 & 68.2 \\
\hline
\end{tabular}

TABLE 3: Pavement peak stress with suspension damping coefficient.

\begin{tabular}{lcccrr}
\hline Suspension damping coefficient/kNs/m & 6 & 10.5 & 15 & 19.5 & 24 \\
\hline Tensile stress/Kpa & 51.692 & 51.543 & 51.244 & 50.894 & 50.361 \\
Horizontal shear stress/Kpa & 62.118 & 62.016 & 61.111 & 61.105 & 59.861 \\
\hline
\end{tabular}

TABLE 4: Pavement peak stress with tire stiffness coefficient.

\begin{tabular}{lcccrc}
\hline Tire stiffness coefficient/kN/m & 1225 & 1750 & 1925 & 2275 & 2800 \\
\hline Tensile stress/Kpa & 49.692 & 51.244 & 51.553 & 52.175 & 54.999 \\
Horizontal shear stress/Kpa & 59.609 & 61.111 & 61.728 & 63.196 & 65.581 \\
\hline
\end{tabular}

TABLE 5: Pavement peak stress with tire damping coefficient.

\begin{tabular}{lcccrr}
\hline Tire damping coefficient/kNs/m & 1.4 & 2 & 2.2 & 2.6 & 3.2 \\
\hline Tensile stress/Kpa & 51.505 & 51.244 & 51.047 & 50.919 & 50.859 \\
Horizontal shear stress/Kpa & 61.165 & 61.111 & 61.093 & 61.054 & 60.993 \\
\hline
\end{tabular}

response. It can be seen from Table 3 that the pavement dynamic stress decreases with increases in the suspension damping coefficient. When the suspension damping coefficient increases $60 \%$, from $15 \mathrm{kNs} / \mathrm{m}$ to $24 \mathrm{kNs} / \mathrm{m}$, the peak horizontal tensile stress at the bottom of base course and the shear stress at bottom of surface layer decrease $1.72 \%$ and $2.05 \%$, respectively. Compared with the suspension stiffness, the effect of suspension damping on the pavement dynamic stress response is relatively small, almost differing by ten orders of magnitude.

5.3. Effects of Tire Stiffness. Table 4 shows the effect of the tire stiffness coefficient on the pavement response. It can be seen from Table 4 that the pavement dynamic stress increases with an increase in the tire stiffness coefficient. When the tire stiffness increases $60 \%$, from $1750 \mathrm{kN} / \mathrm{m}$ to $2800 \mathrm{kN} / \mathrm{m}$, the peak horizontal tensile stress at the bottom of base course and the shear stress at bottom of surface layer increase $7.33 \%$ and $7.31 \%$, respectively. Based on vehicle dynamics, a similar conclusion can also be drawn; that is, if the tire stiffness increases, the vehicle vibrations increase, and the tire dynamic load increase, causing more pavement damage. Compared with the suspension stiffness, the effect of tire stiffness on the pavement dynamic stress response is relatively small.

5.4. Effects of Tire Damping. Table 5 shows the effect of the tire damping coefficient on the pavement response. It can be seen from Table 5 that the pavement dynamic stress decreases with an increase in the tire damping coefficient. When the tire damping increases $60 \%$, from $2.0 \mathrm{kNs} / \mathrm{m}$ to $3.2 \mathrm{kNs} / \mathrm{m}$, the peak horizontal tensile stress at the bottom of base course and the shear stress at bottom of surface layer decrease $0.73 \%$ and $0.19 \%$, respectively. Compared with the tire stiffness, the effect of tire damping on the pavement dynamic stress response is relatively small, differing by ten orders of magnitude. And the effect of tire damping is on the same order of magnitude as suspension damping, when compared to suspension stiffness, is not significant.

\section{Conclusions}

We have presented a study of pavement response under vehicle random dynamic load. The effect of vehicle parameters on the dynamic response of the pavement structure was documented along with the analysis and comparison of the maximum stress distribution of each pavement layer. The main conclusions are as follows:

(1) Under the random dynamic load of a vehicle, the extreme value distributions of vertical stress, horizontal stress, transverse stress, and horizontal shear stress, under the wheel track centerline layers, change with the vehicle driving distance. Their fluctuation frequencies are similar to those of the tire random dynamic load. With increases in pavement depth, the fluctuation strength decreases.

(2) When vehicle parameters vary, the stress extreme distribution curves are inconsistent. By comparing the peak value of each extreme curve, we were able to study the pavement response induced by a vehicle dynamic load with different parameters. Similarly, we were able to analyze the pavement response induced 
by road surface roughness, vehicle speed, pavement structure parameters, and so forth.

(3) For the vehicle parameter investigated in this paper, the pavement dynamic stresses increase with increases in suspension stiffness and tire stiffness but decrease with increases in suspension damping and tire damping. Compared to the stiffness, tire and suspension damping have less of an impact on pavement dynamic load response. When designing a vehicle that would cause less road damage from its random dynamic load, it is necessary to consider and match suspension and tire parameters comprehensively.

\section{Conflict of Interests}

The authors declare that there is no conflict of interests regarding the publication of this paper.

\section{Acknowledgments}

The authors would like to thank Education Department of Jiangsu Province (sponsored by Qing Lan Project) and the Doctoral Fund of Ministry of Education Subject (20120092110044).

\section{References}

[1] P. Cao, C. Zhou, D. Feng, Y. Zhao, and B. Huang, "A 3D direct vehicle-pavement coupling dynamic model and its application on analysis of asphalt pavement dynamic response," Mathematical Problems in Engineering, vol. 2013, Article ID 394704, 8 pages, 2013.

[2] H.-L. Xu, Y. Yuan, T.-J. Qu, and J.-R. Tang, "Dynamic model for a vehicle-pavement coupled system considering pavement roughness," Journal of Vibration and Shock, vol. 33, no. 19, pp. 152-156, 2014.

[3] D.-W. Park, A. T. Papagiannakis, and I. T. Kim, "Analysis of dynamic vehicle loads using vehicle pavement interaction model," Journal of Civil Engineering, vol. 18, no. 7, pp. 2085-2092, 2014.

[4] Y. Chen, J. He, J. Peng, Z. Qi, and X. Ren, "Dynamic analysis of semi-rigid asphalt pavement subjected to simulant dynamic loads," Journal of Southeast University, vol. 40, no. 3, pp. 593598,2010

[5] J. He, M. Gao, P. Wang, Y. Chen, and J. Peng, "Effect of truck velocity on life of visco-elastic asphalt pavement under nonuniform distributed dynamic load," Journal of PLA University of Science and Technology, vol. 10, no. 6, pp. 628-632, 2009.

[6] H. Ding, J. He, Y. Chen, and X. Liu, "Effect of coupling interval of heavy lorry on asphalt pavement," Journal of Highway and Transportation Research and Development, vol. 28, no. 7, pp. 4246, 2011.

[7] W. Ren, Virtual Prototype of Vehicle-Road System Dynamics: The Application of MSC.ADAMS Software, Publishing House of Electronics Industry, Beijing, China, 2005.

[8] P. Lu and Z. Dong, Mechanical Analysis of Vehicle-Asphalt Pavement System, China Communications Press, Beijing, China, 2010.
[9] L. Sun and T. W. Kennedy, "Spectral analysis and parametric study of stochastic pavement loads," Journal of Engineering Mechanics, vol. 128, no. 3, pp. 318-327, 2002.

[10] L. Zhang and H. He, Vehicle Dynamics Theory and Application, National Defense Industry Press, Beijing, China, 2011.

[11] Y. Huang, Pavement Analysis and Design, China Communications Press, Beijing, China, 1998.

[12] D. Liu, G. Li, H. Chen, Z. Kang, and R. Jiang, "Dynamic response of pavement based on random dynamic load of vehicle," Transactions of the Chinese Society of Agricultural Machinery, vol. 42, no. 2, pp. 28-33, 2011.

[13] D. J. Cole and D. Cebon, "Truck suspension design to minimize road damage," Proceedings of the Institution of Mechanical Engineers, Part D: Journal of Automobile Engineering, vol. 210, no. 2, pp. 95-107, 1996.

[14] T. E. C. Potter, D. Cebon, and D. J. Cole, "Assessing 'roadfriendliness': a review," Proceedings of the Institution of Mechanical Engineers, Part D: Journal of Automobile Engineering, vol. 211, no. 6, pp. 455-475, 1997.

[15] H. Li, S.-P. Yang, and S.-H. Li, "Dynamical analysis of an asphalt pavement due to vehicle-road interaction," Journal of Vibration and Shock, vol. 28, no. 4, pp. 86-102, 2009. 


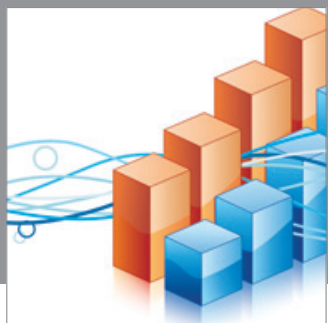

Advances in

Operations Research

mansans

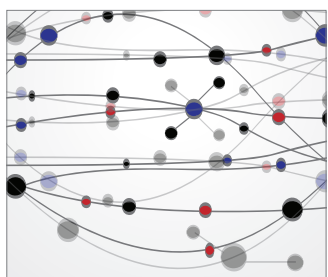

The Scientific World Journal
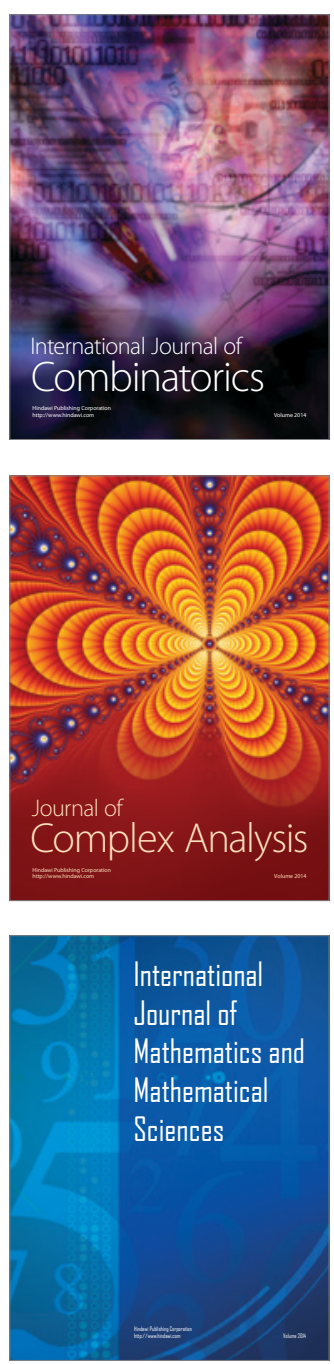
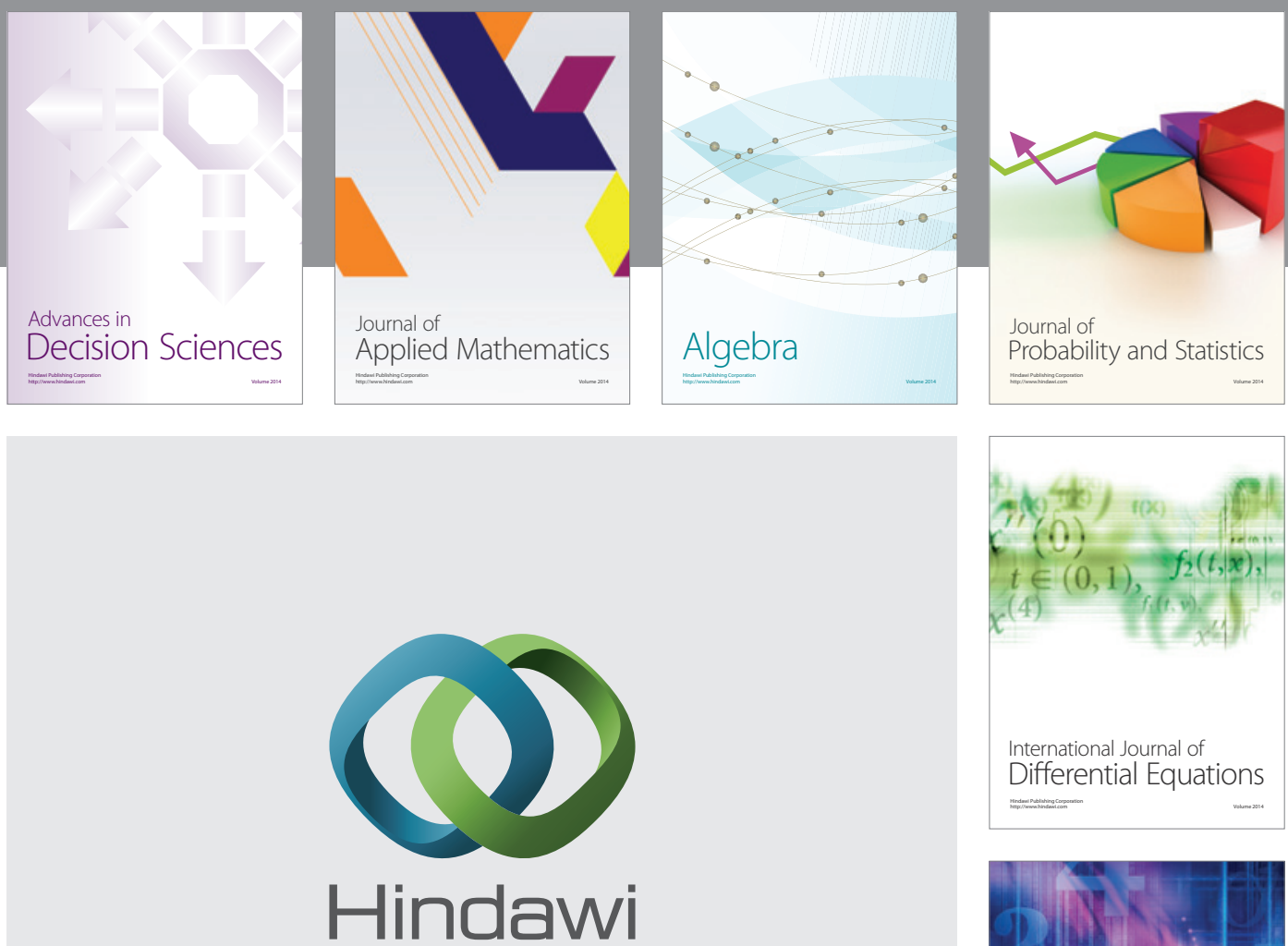

Submit your manuscripts at http://www.hindawi.com
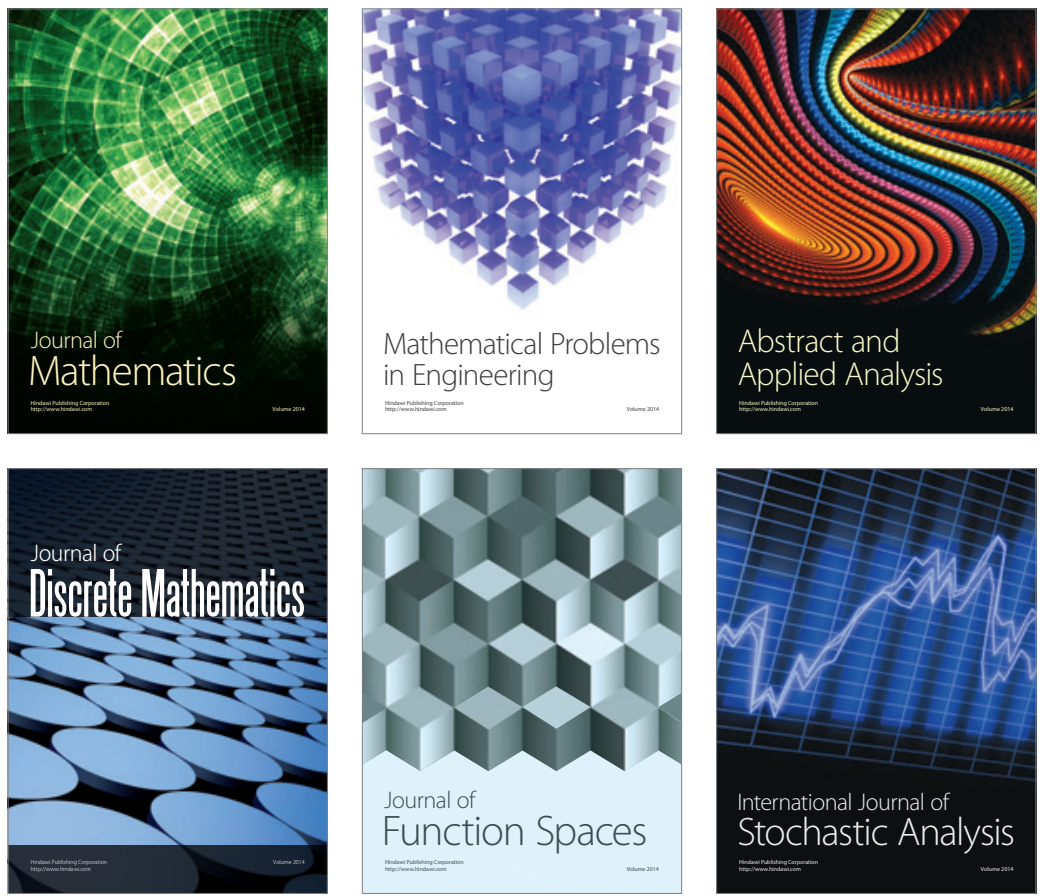

Journal of

Function Spaces

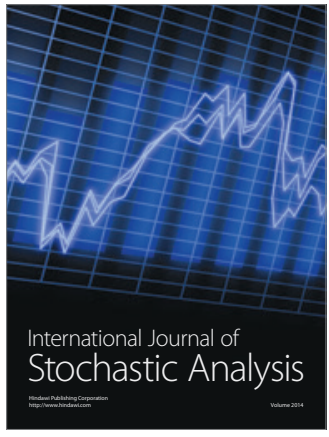

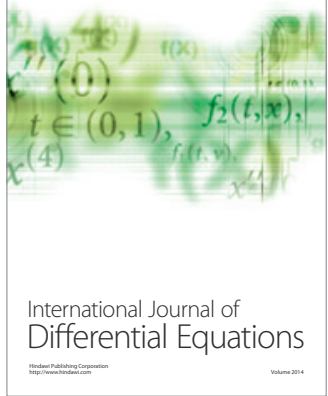
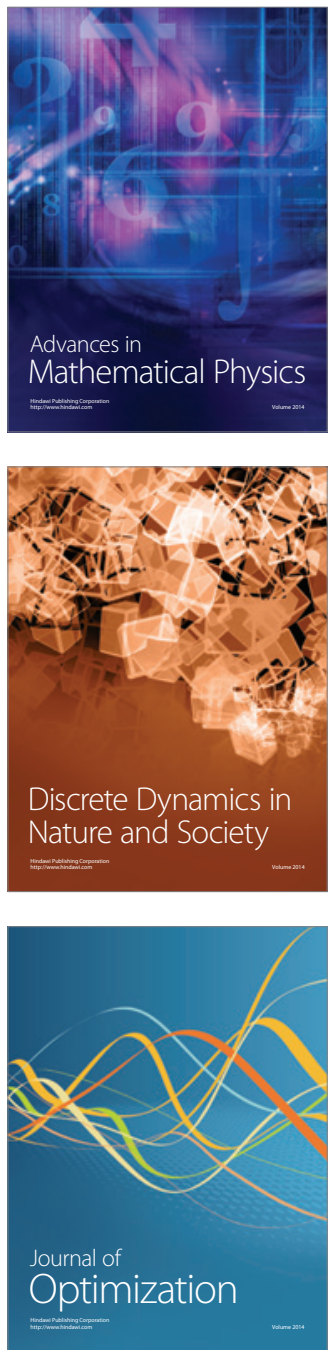